\title{
Caspases control antiviral innate immunity
}

\author{
Huihui Chen ${ }^{1,5}$, Xiaohan Ning ${ }^{2,3,4,5}$ and Zhengfan Jiang ${ }^{3}$ \\ Caspases are a family of cysteine proteases whose functions have been scrutinized intensively in recent years. \\ Beyond their established roles in programmed cell death and inflammatory response, some caspases are also \\ fundamental players in antiviral immunity by fine-tuning the levels of antiviral signaling adapters and cytokines, \\ such as type I interferons, which serves as a major, sophisticated weapon against viruses. Viral infections can result \\ in inflammasome activation and the initiation of cell death, including apoptosis and pyroptosis, and multiple \\ caspases are significantly involved in these processes. This review will focus on the cutting-edge discoveries \\ regarding the multifaceted roles of caspases in antiviral innate immunity. \\ Cellular \& Molecular Immunology (2017) 14, 736-747; doi:10.1038/cmi.2017.44; published online 10 July 2017
}

Keywords: apoptosis; caspases; I-IFNs; inflammasome; innate immunity

\section{INTRODUCTION}

Viral infections can induce systemic immune responses, which are shaped by specific signaling cascades between the host and the pathogen. Host cells are equipped with an array of multiple germline-encoded pattern recognition receptors (PRRs) to detect pathogen-associated molecular patterns (PAMPs). Viral PAMPs are often nucleic acid-based, including double-stranded (ds) RNA, single-stranded (ss) RNA and viral DNA. ${ }^{1}$ In some cases, hosts also detect viral proteins, such as viral fusion glycoproteins, respiratory syncytial virus (RSV)-F protein and Ebola virus GP1 proteins. Current studies have shown that PRRs detect viral nucleic acids mainly consisting of several Toll-like receptor (TLR) family members and various cytosolic sensors. TLRs 3, 7, 8, 9 and 13 can recognize viral nucleic acids in the endosomal compartment. Viral RNA serves as a ligand for both cytosolic NLRP3 inflammasomes and RIG-I-like receptors (RLRs), such as RIG-I, MDA-5 and DHX58 (DEXH box polypeptide 58 or LGP2). ${ }^{2-4}$ Thus far, the cytoplasmic DNA sensors identified include DNA-dependent activator of IFN-regulator factors, DEAD box polypeptide 41, RNA polymerase III, STING (also known as MITA/ERIS/MPYS/ TEM173), cGAS, polyglutamine-binding protein 1 (PQBP1), DNA-dependent protein kinase, ${ }^{6}$ sex-determining region
Y-box $2,{ }^{7}$ meiotic recombination 11 homolog $\mathrm{A},{ }^{8} \mathrm{AIM} 2$ and IFI16 inflammasomes. ${ }^{9-17}$

Upon detecting viral nucleic acids, PRRs activate a set of adapter proteins and relay the signals to downstream transcriptional factors to drive the production of IFNs and IFNstimulated genes (ISGs), induce the secretion of inflammatory cytokines and further initiate pyroptosis, a lytic, programmed cell death.

Insufficient production of IFNs and inflammatory cytokines cause the deficiency of viral infection clearance and leads to chronic viral infections, while excessive amounts of IFNs and inflammatory cytokines contribute to autoimmune and autoinflammatory diseases. Meanwhile, concomitant uncontrolled pyroptosis is also very detrimental to the host. Accordingly, mammals have developed a series of critical downstream mediators to fine-tune the antiviral innate immune system, aiming to balance immune responses against viral pathogens at an appropriate level.

Among the various mediators, caspases are a family of genes situated at the nexus of vital regulatory networks, as they balance inflammation, antiviral innate immunity and cell death. This review will focus on how caspases control antiviral innate immunity on multiple levels.

\footnotetext{
${ }^{1}$ Shenzhen BOLI Pharmaceutical Co., Ltd, Shenzhen, Guangdong 518040, China; ${ }^{2}$ State Key Laboratory of Protein and Plant Gene Research, School of Life Sciences, Peking University, Beijing 100871, China; ${ }^{3}$ Key Laboratory of Cell Proliferation and Differentiation of the Ministry of Education, School of Life Sciences, Peking University, Beijing 100871, China and ${ }^{4}$ Peking-Tsinghua Center for Life Sciences, Beijing 100871, China

${ }^{5}$ These authors contributed equally to this work.

Correspondence: Professor Z Jiang, Key Laboratory of Cell Proliferation and Differentiation of the Ministry of Education, School of Life Sciences, Peking University, Beijing 100871, China.

E-mail: jiangzf@pku.edu.cn

Received: 23 March 2017; Revised: 12 May 2017; Accepted: 12 May 2017
} 


\section{Caspases and signaling pathways}

Caspases are initially synthesized as inactive monomeric zymogens (procaspases) that only obtain catalytic activity upon an appropriate stimulus (Table 1). While 18 mammalian caspases have recently been identified, the newly discovered caspases-15 through -18, except for caspase-16, are absent in placental mammals. The other 12 members of the caspase family are traditionally classified into two groups according to their function. ${ }^{19,20}$ The apoptotic caspases (caspases-2, -3, -6, $-7,-8,-9$ and -10 in mammals) function in the initiation and execution of a morphologically different programmed cell death called apoptosis. The inflammatory caspases (caspases$1,-4,-5$ and -12 in humans and caspases-1, -11 and -12 in mice) mediate innate immune response by cleaving proinflammatory cytokine precursors (for example, pro-IL-1 $\beta$ and pro-IL-18) to initiate inflammation. ${ }^{80}$ Inflammatory caspases are also involved in another programmed cell death known as pyroptosis. ${ }^{19,21-24}$ The functions of caspases-2, -10, -14 and -16 are currently somewhat controversial and enigmatic and are less easily categorized (Table 1).

The mitochondrial-related intrinsic apoptosis pathway is predominantly controlled by the Bcl-2 family and $\mathrm{Bcl}-2$ homology domain-3 (BH3)-only proteins (the pro-death proteins $\mathrm{BAK}$ and $\mathrm{BAX}$ are essential effectors). ${ }^{21,25,26}$ In this pathway, apoptotic stimuli (for example, cytotoxic drugs, DNA damage) activate the $\mathrm{BH} 3$-only proteins, resulting in activation of the pro-apoptotic effectors BAK/BAX and the induction of MOMP (Figure 1). Subsequently, the mitochondrial proteins, such as cytochrome c, efflux into the cytoplasm, initiating the assembly of the apoptosome, including APAF-1, and further activating caspase-9. Ultimately, apoptosis ensues after the

\section{Table 1 Classification of caspases}

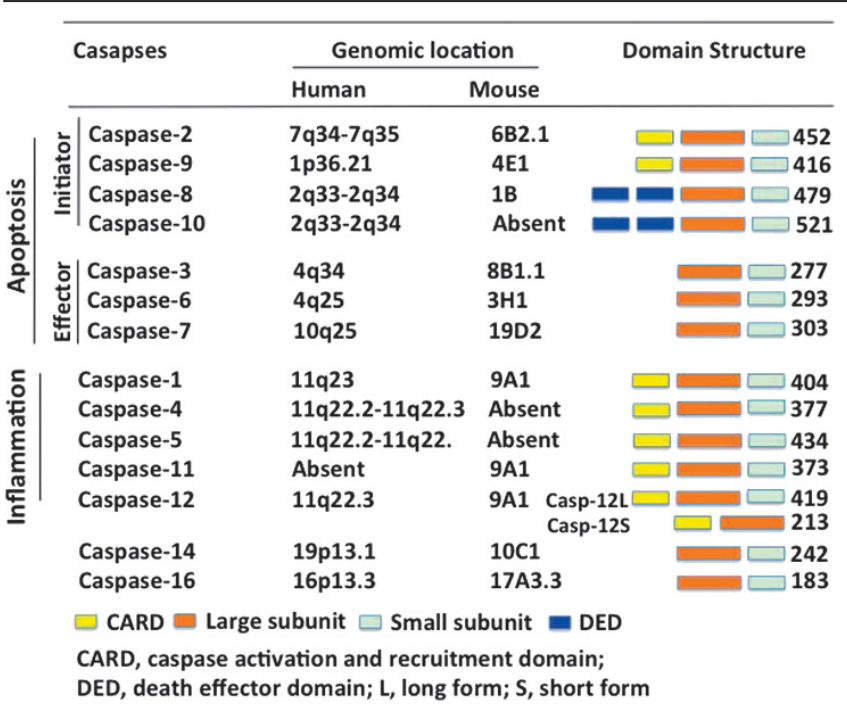

The apoptotic caspases have been subdivided by their mechanism of action into initiator caspases (caspases-2, -8, -9 and -10) and effector caspases (caspases-3, -6 and -7 ). Caspase-10 is only present in the mouse genome. The initiator caspases are involved in various apoptotic pathways, which fall into either the intrinsic or extrinsic category. ${ }^{18,137}$ cleavage and activation of the executioner caspases (caspases3 and -7 ) by caspase- $9^{\text {(refs } 27,28)}$ (Figure 1 ).

The extrinsic apoptosis pathway is death receptor (DR)mediated. DR members include TNF receptor-1, first apoptosis signal (FAS, also known as APO-1 or CD95), DR3, TRAIL-R1 (TNF-related apoptosis-inducing ligand receptor-1 or DR4) and TRAIL-R2 (or DR-5 in human). The DR ligands include tumor necrosis factor (TNF), CD95-L (CD95 ligand or Fas-L), TRAIL (or Apo-L) and TNF-like ligand 1A. Upon activation, the DR death domain recruits adapter proteins to form the DISC comprising FADD, TRADD, caspase-8 (caspase-10 in human cells) and other components. ${ }^{29}$ The activated initiator caspase- 8 is capable of either initiating the extrinsic apoptotic pathway by cleaving and activating the apoptotic effector caspases $(-3,-6,-7)$ or amplifying intrinsic mitochondrial apoptosis by cleaving BID to a truncated form (tBID $)^{30}$ (Figure 1). In certain conditions, when the levels of $\operatorname{FLIP}_{\mathrm{L}}$ (long isoform of the FLICE-like inhibitory protein) are decreased and upon genotoxic stress, caspase- 8 associates with RIPK1 and FADD to form a multiple protein complex called the 'ripoptosome', leading to apoptosis ${ }^{6,31-33}$ (Figure 1).

Inflammatory caspases function as central adapters of innate immunity, mainly by controlling the assembly of larger, multiple protein complexes called inflammasomes. Canonical inflammasomes are often characterized as scaffold proteins containing members of the NLR (nucleotide-binding-andoligomerization domain and leucine-rich-repeat-containing) family, the AIM2-like receptor family or the tripartite motif (TRIM, of which pyrin is the only member of inflammasomes) family and caspase- 1 molecules together to trigger the autocleavage and activation of caspase- $1 .{ }^{34}$ The inflammasomes currently known to be engaged in antiviral innate immunity include the NLRP3 inflammasome,, $35-38$ the RIG-I inflammasome ${ }^{39}$ and the AIM2 inflammasome. ${ }^{10-12}$ The noncanonical inflammasomes comprise caspases- 4 and -5 in humans and caspase-11 in mice, which directly recognize lipopolysaccharides (LPS) ${ }^{40-43}$ Both canonical caspase- 1 and noncanonical caspase-11 inflammasomes trigger two sets of inflammatory responses: the cleavage and release of proinflammatory cytokines, including IL- $1 \beta$, IL-18 and IL- $33,{ }^{44}$ and the induction of pyroptosis. ${ }^{34,45}$

\section{Caspase-1-dependent antiviral inflammasomes}

Caspase-1 plays a vital role in inflammatory responses by assembling a large $(700 \mathrm{kDa})$ molecular structure called an inflammasome. ${ }^{46}$ The conversion of pro-caspase- 1 into catalytically active caspase- 1 is tightly connected with the maturation of pro-IL-1 $\beta$, pro-IL-18 and most likely pro-IL-33 in some cases. To date, four distinct caspase-1-dependent inflammasomes have been identified as being involved in antiviral innate immunity: the RIG-I inflammasome, ${ }^{39,47}$ the AIM2 inflammasome, ${ }^{10-12}$ the IFI16 inflammasome and the NLRP3 inflammasome. ${ }^{2,36-38}$ The adapter ASC provides a platform between RIG-I, NLRP3, AIM2 or IFI16 and procaspase-1 through a homotypical association with $\mathrm{N}$-terminal PYDs (pyrin domains) and C-terminal CARDs. Once the 


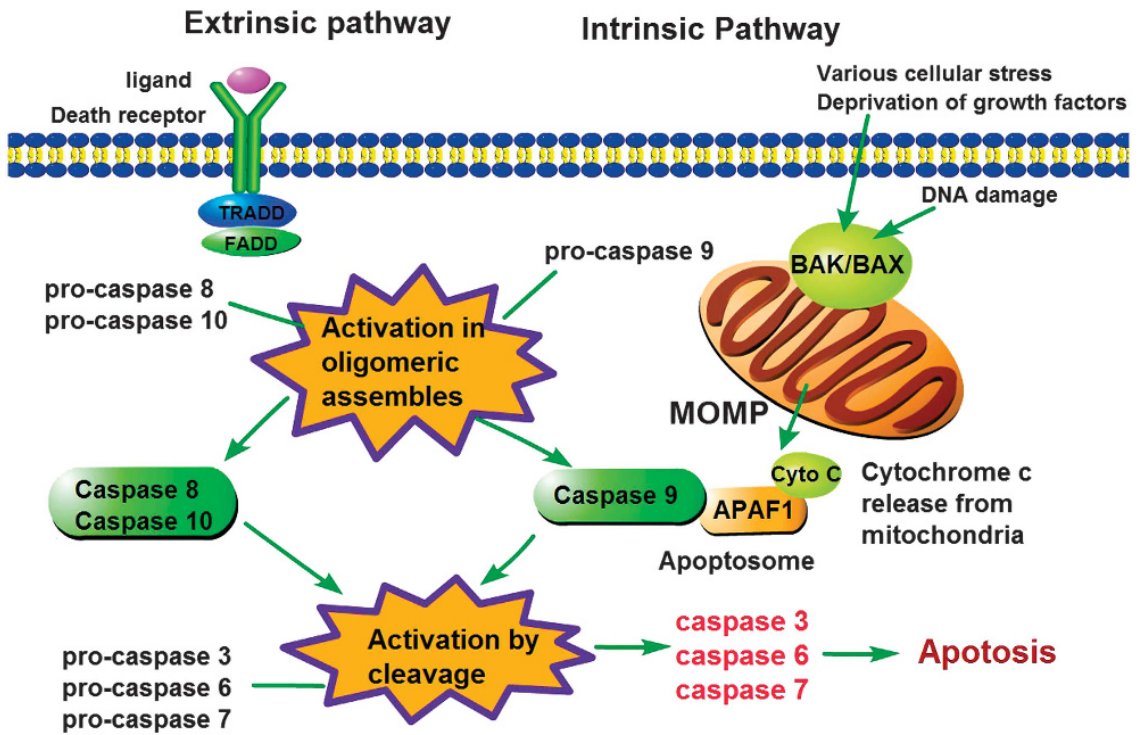

Figure 1 Caspases in extrinsic and intrinsic apoptosis. The extrinsic apoptosis pathway is activated by ligand binding and the death receptor, which then recruits TRADD or FADD to form a DISC complex, resulting in the activation of initiator caspase-8 or -10 . These caspases then directly cleave and activate the effector caspases-3, -6 and -7 , effectively executing cellular apoptosis. Alternatively, the intrinsic apoptotic pathway can be activated by intrinsic stimuli, including various cellular stressors, DNA damage and growth factor deprivation. Subsequently, the activation of BAK and BAX or the inactivation of anti-apoptotic BCL-2 family members leads to MOMP and the release of mitochondrial factors, such as cytochrome $c$. Cytochrome $c$ binding to APAF- 1 is important for the activation and oligomerization of caspase-9 to form the apoptosome. The activation of caspase-9 then initiates apoptosis by activating the effector caspases. FADD, FAS-associated death domain; TRADD, TNFR-associated death domain; DISC, death-inducing signaling complex; caspases, cysteinyl aspartate proteinases; BAX, BCL-2-associated X protein; BAK, BCL-2 antagonist or killer; MOMP, mitochondrial outermembrane permeabilization; APAF-1, apoptotic protease-activating factor 1 .

filamentous inflammasome complex is assembled, pro-caspase1 is initially autoproteolytically cut into a p35 CARDcontaining fragment and a p10 fragment. Sequentially, p35 is further digested into a p20 fragment and a CARD, and then two p20 subunits heterodimerize with two p10 subunits to produce a bioactive caspase- 1 . Activated caspase- 1 then mediates the processing of pro-IL- $1 \beta$ and pro-IL-18 at cysteine residues adjacent to aspartic acid residues. The secreted and active cytokines lead to downstream inflammatory responses (Figure 2).

RIG-I inflammasome. RIG-I has been shown to be involved in the recognition of RNA viruses, including Newcastle disease virus, vesicular stomatitis virus (VSV), Sendai virus $(\mathrm{SeV})$, rabies virus, hepatitis virus (HCV), Japanese encephalitis virus, influenza A virus, measles virus and RSV. ${ }^{48-55}$ Upon viral infection, RIG-I recruits the mitochondrial adapter MAVS/ TRAF3/6 (TNF receptor-associated factor 3/6) signalosome and then activates IKKe and IRF3/7 to induce IFN signaling. Current studies have shown that RIG-I is also involved in inflammatory responses. Upon VSV infection or $5^{\prime}$-triphosphate RNA transfection, RIG-I directly activates inflammasome signaling by recruiting caspase-1 in an ASC-dependent manner (Figure 2). Furthermore, RIG-I reportedly induces the processing and secretion of IL-18 by activating caspase- 3 in response to viral infection. ${ }^{47}$
AIM2 and IFI16 inflammasomes. AIM2 and IFI16 belong to a family of interferon-inducible HIN-200 proteins, which contain an $\mathrm{N}$-terminal pyrin domain for sensing cytoplasmic DNA and a C-terminal domain (oligonucleotide/oligosaccharidebinding domain) for interacting with ASC to activate caspase- 1 and caspase- 8 . Caspase- 1 mediates IL- $1 \beta$ and IL-18 maturation and pyroptosis, while caspase- 8 induces apoptosis. The family includes IFI16, MNDA, IFIX and AIM2 in humans and IFI202, IFI203, IFI204, IFI205, Pyin1 and AIM2 in mice. Four groups have discovered that AIM2 senses cytoplasmic dsDNA, including viral DNA (for example, adenovirus and retrovirus). A report using cultured cells showed that vaccinia virus (VACV) and mouse cytomegalovirus (mCMV) triggered the autoactivation of caspase-1 through AIM2. Moreover, Aim2-deficient mice infected with mCMV revealed low IL-18 levels, decreased IFN $\gamma$-expressing nature killer cells and higher mCMV viral titers compared to control mice. ${ }^{56}$ Intriguingly, current work revealed that AIM2 could also recognize RNA viruses, such as Chikungunya virus (CHIKV) and West Nile virus in a caspase-1-dependent manner in human dermal fibroblasts. Similarly, inhibition of the inflammasome via caspase-1 silencing enhanced CHIKV replication in resident skin cells. ${ }^{57}$ Furthermore, skin fibroblasts infected with Zika virus (a ssRNA virus) displayed elevated levels of AIM2 and IL-1 $\beta$ transcripts. ${ }^{58}$ More intensive studies are needed to explore the mechanism of how AIM2 recognizes RNA viruses 


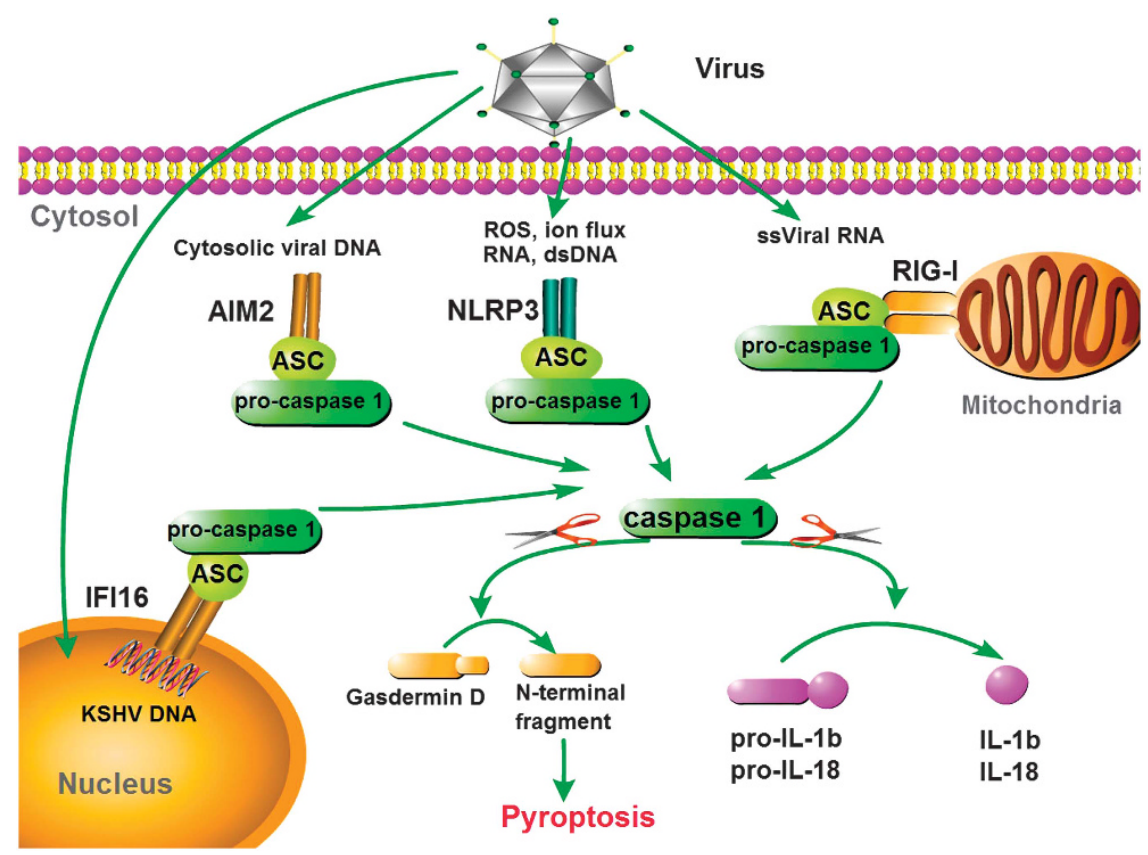

Figure 2 Caspase-1-mediated inflammasomes involved in antiviral defense. In responses to viral PAMPs, RIG-I, NLRP3, AIM2 and IFI16 assemble caspase-1-activating inflammasome complexes in an ASC-dependent manner. Activated caspase-1 drives the cleavage and maturation of the proinflammatory cytokines pro-IL-1 $\beta$ and pro-IL-18. Inflammatory caspases cleave gasdermin D, causing pyroptosis, which promotes the release of matured IL-1 $\beta$ and IL-18. The NLRP3 inflammasome recognizes multiple PAMPs, including viral RNA, in combination with ion flux or ROS. The RIG-I and AIM2 inflammasomes recognize viral ssRNA and dsDNA, respectively. The AIM2 inflammasome could recruit caspase-8 to induce apoptosis. The IFI16 inflammasome specifically recognizes KSHV dsDNA in the nucleus. RIG-I, retinoic acid inducible gene-I; NLRP3, nucleotide-binding oligomerization-like receptor family, pyrin domain-containing protein 3; AIM2, absent in myeloma 2; IFI16, $\gamma$-interferon-inducible protein 16; ASC, apoptosis-associated speck-like protein containing a caspase recruitment domain; IL-1 $\beta$, interleukin-1 $\beta$; IL-18, interleukin-18; KSHV, Kaposi's sarcoma-associated herpes virus.

to activate inflammasomes and the subsequent procession of caspase- 1 and IL-1 $\beta /$ IL-18.

AIM2 is located in the cytosol to recognize viruses, and the AIM2-like receptor IFI16 is localized predominantly in the nucleus, despite small amounts of cytosolic IFI16 being observed in some cells. In addition to the engagement of I-IFN induction in response to viral dsDNA, such as in VACV and herpes simplex virus type 1 (HSV-1), IFI16 has also been proven to sense KSHV genomes and associate with ASC and pro-caspase- 1 in the nucleus ${ }^{59}$ (Figure 2). However, the mechanism of IFI16 inflammasome redistribution to the cytoplasm remains unknown. Other studies have showed that IFI16 induces the expression of both I-IFNs and caspase-1dependent inflammatory cytokine maturation in response to human immunodeficiency virus-1 (HIV-1) replication. ${ }^{60-62}$

NLRP3 inflammasomes. Until now, the NLPR3 inflammasome is the most well-studied member of the NLR family, and it can activate caspase- 1 and induce the production of IL- $1 \beta$ and IL-18 in response to a wide range of PAMPs and endogenous and environmental stimuli. ${ }^{34}$ Until now, NLRP3 is the only member of this family shown to be engaged in viral infection, including influenza $\mathrm{A}$ virus, $\mathrm{SeV}$, vaccinia virus and encephalomyocarditis virus. ${ }^{2,35,37,39}$ Although several studies have revealed that the shared mechanism of a diversity of potential activators can enable NLPR3 to oligomerize and recruit both ASC and pro-caspase-1 through the PYD domain, there is little evidence of NLRP3 directly binding to these ligands (Figure 2). Dual distinct signaling levels account for NLRP3 activation in terms of viral infection. ${ }^{63-65}$ The entry of influenza A virus into the host cell leads to the release of ions and the production of ROS by NADPH (nicotinamide adenine dinucleotide phosphate) in the cytosol. In the meantime, the viral M2 channel is induced and transferred to the acidified trans-Golgi apparatus, facilitating the efflux of hydrogen ions to activate the NLRP3 inflammasome. Likewise, ROS acts as secondary messengers to augment the virus-induced NLRP3 inflammasome. ${ }^{2,65}$ Modified vaccinia virus Ankara-mediated NLRP3 inflammasomes have also been demonstrated to require TLR2-dependent signaling. ${ }^{66}$

\section{Caspase-dependent pyroptosis}

Cumulative reports have discovered that inflammasomes are not only capable of maturing proinflammatory cytokines, but also promote 'pyroptosis', a distinct inflammatory caspasedependent cell death. ${ }^{67}$ Accordingly, the inflammatory caspases-1, $-4,-5$ and -11 are also called pyroptotic caspases $^{40,41,68,69}$ (Figure 2).

Pyroptosis cell death was initially observed in Shigella flexneri-infected macrophages in 1992, and it was defined as apoptosis because it shared common features, such as nuclear condensation, DNA fragmentation and caspase dependence. ${ }^{70}$ 
It was not until 2001 that researchers further determined that pyroptosis characteristics are distinct from those of apoptosis. First, pyroptosis is programmed by inflammatory caspases. Second, inflammatory caspase activation leads to plasma membrane pore formation and, thus, permeabilizes the cells to small molecules, such as water and ions. Third, the water/ ion influx and osmotic lysis cause massive leakage of cytosolic substances. ${ }^{68,71}$ Fourth, pyroptotic cell death requires the cleavage of gasdermin $\mathrm{D}$ by caspases-1, $-4,-5$ and -11 , generating the $\mathrm{N}$-terminal fragment responsible for pyroptosis initiation. However, the C-terminal fragment remains an enigma. ${ }^{72-74}$ Finally, pyroptosis causes DNA damage, whereas the nucleus remains intact following the activation of ADPribose polymerase and consummation of NAD+ and ATP. ${ }^{75}$ Summarily, innate immunity is armed with pyroptosis to dispose of pathogen-laden cells and eliminate invading microbe protective niches by enabling them to be removed by a secondary phagocyte.

Pyroptosis is triggered by either caspase- 1 or caspases- $4,-5$ and -11 , and proinflammatory cytokine maturation is dispensable for pyroptosis. However, some differences exist between pyroptosis induced by caspase- 1 and pyroptosis induced by caspases-4, -5 and $-11 .{ }^{76-80}$ Casapase-1-dependent pyroptosis is initiated by various ligands, which activate canonical inflammasomes, and occurs mainly in macrophage or dendritic cells, while pyroptosis dependent upon caspases-4, -5 and -11 is directly triggered by bacterial stimuli, for which the production of IL- $1 \beta / \mathrm{IL}-18$ is nearly negligible. ${ }^{81,82}$

Caspase- 1 is currently the only member known to be involved in virus-induced pyroptosis. During HIV infection, caspase-1-dependent pyroptosis is critical for $\mathrm{CD}^{+}$T-cell depletion, implicating HIV pathogenesis. ${ }^{61}$ It is remarkably noted that caspase-1-deficient mice develop normally, disputing that the blockade of caspase-1 activity exerts beneficial rather than detrimental effects in HIV patients. Despite these important roles, the mechanisms of how inflammatory caspases drive pyroptosis need further study.

\section{Caspases regulate the antiviral innate signaling pathways} cGAS-STING antiviral pathway. Recent work has demolished the traditional definition of apoptotic caspases, as it has become obvious that apoptosis caspases can control antiviral innate immunity through non-death processes. Two studies have showed that caspases-9, -3 and -7 involved in the intrinsic apoptotic pathway negatively regulate the induction of I-IFNs response by controlling cGAS and STING signaling 83,84 (Figure 3).

Succumbing to DNA viral infection, the cGAS/STING pathway is triggered by the recognition of cytosolic dsDNA, including dsDNA from HSV-1, murine gammaherpesvirus 68,

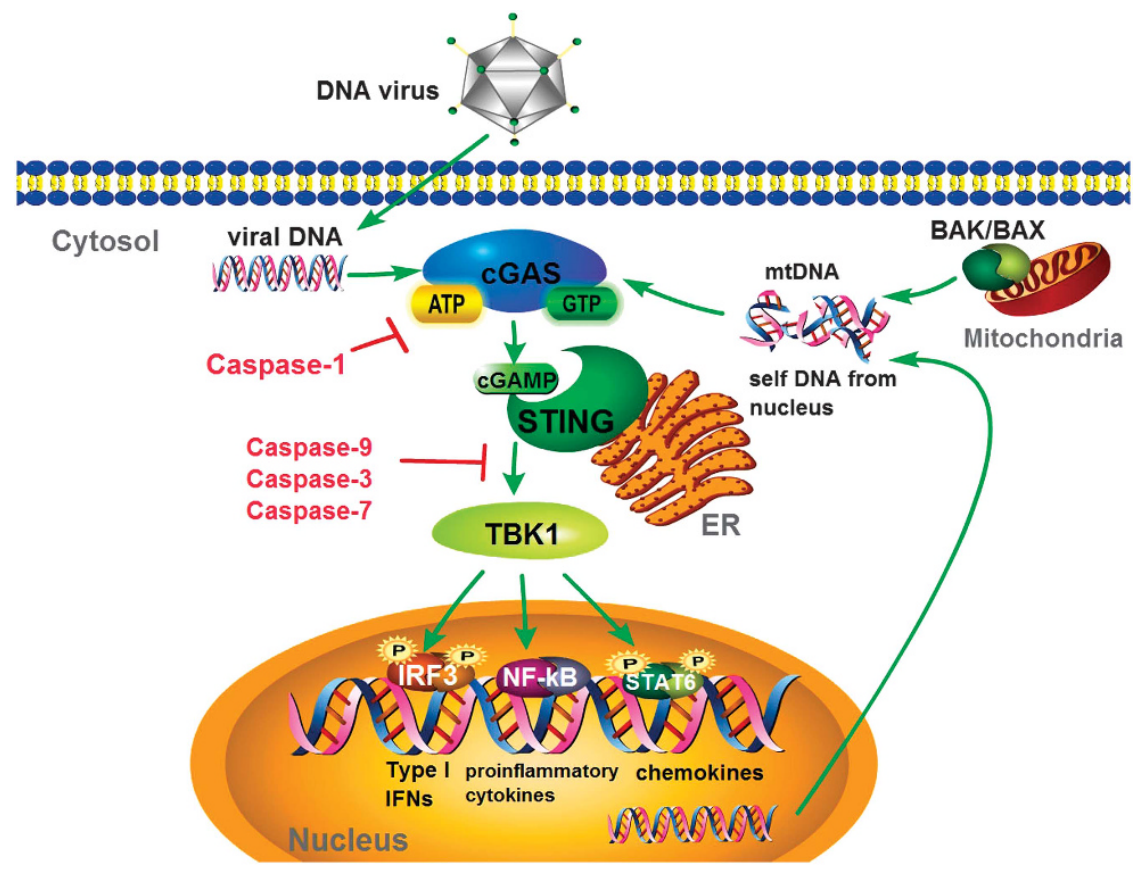

Figure 3 Caspases control the cGAS-STING signaling pathway. Cytosolic DNA from virus or self-DNA from mitochondria or the nucleus could activate cyclic GMP-AMP synthase cGAS, which catalyzes the production of cGAMP in the presence of ATP and GTP. cGAMP binds and activates the ER-localized adapter protein STING, which then recruits and activates TBK1. This is followed by the phosphorylation and activation of the transcription factors IRF3, NF-кB and STAT6, leading to I-IFN, proinflammatory cytokines and chemokine production. The apoptotic caspases-9, -3 and -7 could inhibit cGAS/STING/TBK1/IRF3-mediated IFN $\alpha / \beta$ production, while the inflammatory caspase-1 could cleave cGAS to control innate immunity during inflammasome activation. cGAS, cGAMP/cAMP synthase; STING, stimulator of IFN genes; TBK1, Tank-binding kinase 1; IRF3, IFN regulatory factor 3; NF-кB, nuclear factor $\kappa \mathrm{B}$; STAT6, signal transducer and activator of transcription 6; mtDNA, mitochondrial DNA. 
KSHV, VACV, adenovirus, human cytomegalovirus, human papillomavirus, hepatitis B virus, by the DNA sensor cGAS ${ }^{85-92}$ In addition, retroviruses, such as HIV-1 and human T-cell leukemia virus-1, which contain ssRNA genomes, require reverse-transcribed DNA to propagate their infection. With the aid of the proximal sensor PQBP1, cGAS recognizes immunogenic HIV-1 DNA and then gains its enzymatic activity to synthesize the secondary messenger $2^{\prime} 3^{\prime}$-cGAMP from ATP and GTP, following the interaction and activation of the endoplasmic membrane protein STING through a series of structural changes. Activated STING recruits the kinase TBK1 to phosphorylate the transcriptional factors IRF3 and STAT6, which robustly stimulates I-IFNs (IFN $\alpha$ and IFN $\beta$ ) and STAT6-specific chemokines, respectively. ${ }^{93,94}$ Moreover, STING also activates IKK to phosphorylate I $\mathrm{KB} \alpha$ (inhibitor of $\kappa \mathrm{B})$ following its degradation and NF- $\kappa \mathrm{B}$ activation, thus controlling DNA, cytokine production and cell survival (Figure 3)..$^{95}$

In addition to viral DNA stimulation, HSV-1 has been shown to induce cell stress and stimulate the generation of mtDNA. ${ }^{96}$ In addition, intrinsic apoptosis reportedly mediates BAK/BAX-mediated mitochondrial damage to release mtDNA into the cytosol, which, in turn, triggers the cGAS/STINGmediated antiviral immune responses and establishes a potent state of viral resistance. By contrast, mtDNA-triggered cGAS/ STING-dependent I-IFN production can be inhibited by the activation of apoptotic caspases-3, -7 and -9 , indicating the crucial function of caspases in restraining cell-intrinsic immune response to maintain immunological silence in apoptotic cells $^{83,84}$ (Figure 3). A deficiency in caspase- $9,-3$ or -7 results in an intensive resistance to viral infection both in vitro and in vivo. The HSC (hematopoietic stem cell) niche is highly sensitive to the effects of I-IFNs, which predominantly determine the cellular vulnerability to viral infections. The loss of either caspase- $9,-3$ or -7 impairs HSC function, ascribed by the elevated level of mtDNA-triggered apoptotic I-IFNs. Moreover, the pharmaceutical inhibition of caspases could perturb I-IFN production and HSC dysfunction. The mechanisms of the caspase-dependent suppression of I-IFNs elucidated that either caspase- 3 or -7 could prevent cGAS activation by detecting mtDNA or inhibiting some components of I-IFN signaling, whose intermediates, such as IRF3, are reportedly targeted by caspases. ${ }^{97}$ However, the precise contribution of caspases to the regulation of I-IFNs signaling needs to be further established.

In addition to the apoptotic caspases, inflammatory pyroptotic caspases are also found to negatively regulate the cGAS/ STING pathway during inflammatory activity. ${ }^{98}$ Jiang's group was the first to identify that pyroptotic caspases directly cleave cGAS at the $\mathrm{N}$ terminus upon inflammasome activation, resulting in reduced cGAMP production and cytokine secretion. Caspase-1 has been shown to bind directly and cleave human cGAS at $\mathrm{D}^{140 / 157}$ during canonical inflammation activation, releasing the less-conserved $\mathrm{N}$ terminus of human cGAS (hcGAS-N160) and the highly conserved nucleotidyltransferase/Mab 21 domains. Current studies have demonstrated that $h$ cGAC-N160 promotes the activity of full-length
hcGAS upon sensing host- or pathogen-derived dsDNA. ${ }^{137}$ Compared to WT mice, peritoneal macrophages from ASC -/- and Casp $1^{-/-}$mice were shown to produce significantly higher levels of I-IFNs and IL-6, rendering host resistance to DNA viruses, such as HSV-1 or Vaccinia virus infection, but not RNA virus infection, such as SeV. Similarly, inhibition of the caspase-1 inflammasome potentiates DNA virus-induced I-IFN production. Alternatively, upon LPS-induced noncanonical inflammasome activation, caspases- $-4,-5$ and -11 cleave cGAS in a manner distinct from caspase-1.

All these data suggest that apoptotic/pyroptotic caspases can either positively or negatively regulate virus/DAMP (damageassociated molecular pattern)-induced I-IFN signaling and canonical/noncanonical inflammatory responses.

RIG-I/Mda-5-mediated antiviral pathway. Caspase-8 and -10 are recognized as initiator caspases that induce DR-mediated extrinsic apoptosis (for example, Fas, TNFR and TRAIL). Recently, more studies have emphasized the relationship between caspases- 8 and -10 and antiviral I-IFN production. ${ }^{100-104}$ The cytosolic RNA helicase RIG-I and Mda-5 sense RNA viruses and then recruit the mitochondrial adapter MAVS (also called IPS1/VISA/CARDIF) to activate transcription factors, including IRF3 and NF- $\mathrm{KB}$. The kinase RIPK1 is recruited by MAVS at mitochondria and undergoes K63-linked polyubiquitination following the activation of antiviral responses via IRF3-dependent I-IFN production. Remarkably, caspase- 8 cleaves the polyubiquitinated RIPK1 to release a RIPK1 fragment, which inactivates IRF3 and suppresses RIG-I/Mda-5-mediated antiviral I-IFN responses ${ }^{101}$ (Figure 4). In response to RNA viral infection (for example, $\mathrm{SeV}$ and VSV) or poly (I:C) stimulation, caspase-8 deficiency in fibroblastoid cells or hepatocytes results in the increased activation of IRF3. ${ }^{101}$ Moreover, RIG-I-mediated signaling activates caspase- 8 to initiate an important intermediate process in the ubiquitination/proteasome-dependent degradation of IRF3, modulating dsRNA-dependent gene induction. ${ }^{105}$ Interestingly, another group has reported the opposite result. By interacting with FADD, caspases- 8 , and - 10 are required for RIG-I/Mda-5-induced NF- $\kappa B$ and IRF3 activation. Caspase-10 knockdown cells and cells isolated from caspase-8-deficient mice display an impaired ability to produce proinflammatory cytokines in response to dsRNA. ${ }^{100}$ Analogously, compared to the full-length form, transfection with the DED domain of caspase- 8 and -10 enhances the activity of NF- $\kappa$ B. Furthermore, dsRNA treatment or overexpression of a constitutively active RIG-I/Mda-5 mutant significantly abolished NF- $\mathrm{\kappa B}$ activation in murine embryonic fibroblasts isolated from both caspase-8 knockout mice and HEK293T cells in which caspase8 and -10 was knocked down. Interestingly, IFN- $\beta$ stimulation remains intact in caspase-8-deficient cells. The above data suggest that caspase- 8 and -10 are critical elements for RIG-I/ Mda-5-mediated NF- $\kappa B$ antiviral signaling. ${ }^{100,106}$

In addition to its effective function in I-IFN stimulation (IFN- $\alpha / \beta)$, MAVS is suggested to mediate apoptosis from its mitochondrial site of action upon RNA viral infection, such as 


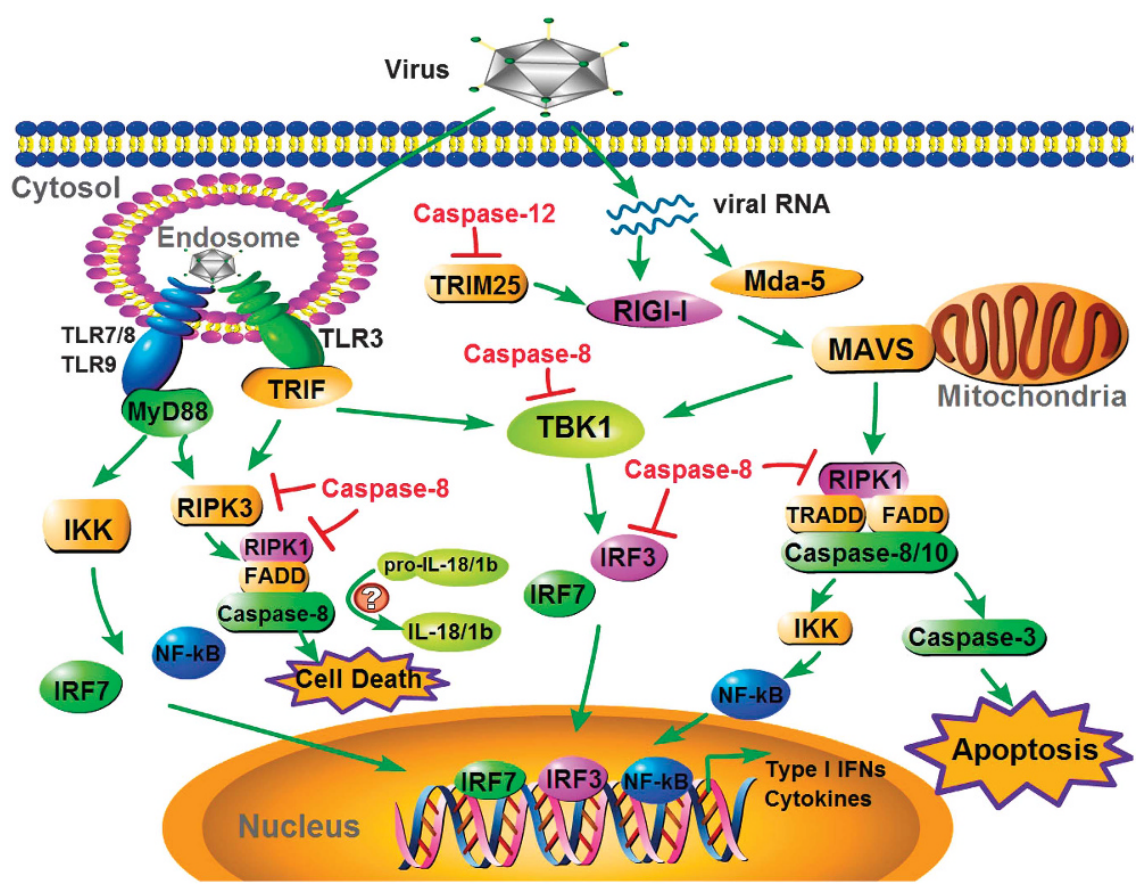

Figure 4 Caspases regulate RLR and TLR antiviral signaling. RIG-I and Mda-5 recognize viral RNA and associate with MAVS localized in mitochondria and then transduce signal through multiple adapters, leading to the activation of IRF3/7 via the kinase TBK1. Simultaneously, MAVS triggers NF-KB via TRADD, FADD and caspases-8 and -10. In addition, host cells could mount a caspase-3mediated apoptotic response to some viruses, such as SeV, via MASV. The RNA genomes of viruses internalized in the endosomes are detected by members of the TLR family of receptors, including TLR3, TLR7, TLR8 and TLR9, which recruit adapter proteins, such as TRIF and MyD88. Subsequently, TRIF and MyD88 transduce signals to the downstream transcription factors IRF3/7 and NF-KB via TBK1 and the IKK complex, respectively. Notably, in some cell types, both TRIF and MyD88 can trigger RIPK3 and further form a cell deathinducing complex that includes RIPK1, FADD and caspase-8. Caspase- 8 is also reportedly involved in the maturation of pro-IL-18/1 $\beta$. Caspase-12 could suppress RIG-I signaling by cleaving TRIM25. By inhibiting multiple adapters in the RLR/TLR antiviral signaling pathway, such as TBK1, IRF3, RIPK1 and RIPK3, caspase-8 has even more powerful functions in controlling antiviral innate immunity. MDA-5, melanoma differentiation-associated protein 5; MAVS, mitochondrial antiviral signaling protein; TRIF, TIR-domain-containing adapter-inducing interferon- $\beta$; MyD88, myeloid differentiation primary response gene; RIPK1, receptor-interacting serine/threonine-protein kinase 1 ; IKK, inhibitor of NF-kB kinase.

$\mathrm{SeV}$, dengue virus, reovirus and semliki forest virus (SFV). ${ }^{107-111}$ MAVS-mediated apoptosis requires the activation of caspases-3, -8 and -9 , and $\mathrm{MAVS}^{-1-}$ fibroblasts are resistant to $\mathrm{SeV}$-induced apoptosis. ${ }^{108,110,112,113}$ It has been observed that MAVS-deficient cells have decreased caspase- 8 and -3 activity. Moreover, SFV reportedly requires MDA-5 and MAVS but not TRAF2, IRF3/7, IFN- $\beta$, IFNAR, PKR or RNase $L$ for apoptosis induction. This pro-apoptotic pathway involves the SFV-induced recruitment of caspase- 8 to MAVS in mitochondria, and FADD is unnecessary. Sequentially, activated caspase8 cleaves and activates caspase- 3 for apoptosis using a Bax/Bakindependent mechanism. ${ }^{114}$ Furthermore, HRV1a (human rhinovirus 1a) infection was shown to induce a stronger increase of IFN- $\beta$ than caspase-3-mediated MAVS cleavage and apoptosis. ${ }^{115}$ Virus-encoded viroporins, such as $6 \mathrm{~K}$ protein from Sindbis virus, $2 \mathrm{~B} / 3 \mathrm{~A}$ from poliovirus, $\mathrm{E}$ protein from mouse hepatitis virus, M2 from influenza A virus and p7/NS4A from HCV, can change the permeability of host cells and have a critical influence on virus budding. These viroporins are reportedly able to induce caspase-3-dependent apoptosis in a mitochondrial manner. ${ }^{116}$
Caspase-12 was recently suggested to control RIG-I signaling cascades. ${ }^{117}$ Caspase-12 has been shown to regulate the TRIM25-mediated ubiquitination of RIG-I, leading to the downregulation of I-IFN response. Caspase-12-deficient mice were shown to be highly predisposed to West Nile virus encephalitis and to have aggravated neurological symptoms $^{117,118}$ (Figure 4).

TLRs antiviral pathway. TLR3 has been identified as a key sensor for viral dsRNA or its analog poly (I:C) and interacts with a vital TLR adapter, TRIF, culminating in the activation of $\mathrm{NF}-\kappa \mathrm{B}$ and IRF3 and the transcriptional induction of their target genes, including TNF- $\alpha$, IL- 6 and IFN- $\alpha / \beta$ (Figure 4 ).

Picornavirus infection-induced TLR3/TRIF reportedly recruits a $2 \mathrm{MDa}$ intracellular cell death complex called the 'ripoptosome', containing RIP1, FADD, caspases- 8 and -10 and isoforms of the caspase inhibitor cFLIP. cFLIP $(\mathrm{S})$ enhances ripoptosome assembly, while cFLIP(L) exerts the opposite function. The caspase-8-cFLIP(L) complex has adequate catalytic activity to cleave the RIP1 kinase. Caspase- 8 reportedly negatively controls TLR3 signaling in macrophages and BM- 
derived dendritic cells via caspase-8-interacting proteins, such as FADD, cfLIP, RIP and TRAIL-R ${ }^{119}$ (Figure 4).

$\mathrm{NF}-\mathrm{KB}$ plays a vital role in the transcriptional activation of many inflammation-related and anti-apoptotic genes in response to inflammatory cytokines, PAMPs, growth factors and cellular stress states. NF- $\mathrm{KB}$ is located in the cytosol in an inactive form, which is inhibited by IкB. After multiple signaling cascades, IKK phosphorylates IKB, and the subsequent degradation of I $\kappa \mathrm{B}$ releases NF- $\kappa \mathrm{B}$ after it translocates to the nucleus and, finally, activates its targets. In B cells, caspase-1 was shown to activate NF- $\mathrm{KB}$ to induce inflammation in a different manner. ${ }^{120}$ This novel signaling is mediated by the CARD of procaspase- 1 and results in the stimulation of NF- $\kappa B$ and p38 MAPK in a RIP2-dependent manner. In addition, this pathway is not shared by caspase- 11 and $-12 .^{120,121}$

Recent data have indicated that caspase- 8 is critical for the activation of NF- $\mathrm{kB}$ signaling, which results in the induction of proinflammatory cytokines. However, many studies of the function of caspase- 8 in modulating NF- $\mathrm{KB}$ signaling have thus far been restricted in anti-bacterial/fungal innate immunity, adaptive immunity and cancer. ${ }^{80,122-125}$ Moreover, to date, there is no consensus on the molecular mechanism underpinning how caspase- 8 mediates NF- $\mathrm{\kappa B}$ signaling or whether caspase- 8 can regulate the NF- $\mathrm{\kappa B}$ activation involved in antiviral innate immunity, and these phenomena need to be studied in more detail. Caspase- 8 has also been demonstrated to exert critical functions in B-cell activation and expansion in response to TLR3 but not TLR9 by associating with the IKK complex and, in turn, modulating NF- $\mathrm{KB}$ translocation. ${ }^{124}$ These findings are consistent with the increased susceptibility of human patients deficient for caspase- 8 to viral infections. ${ }^{122}$

In addition, the existence of the involvement of TRIF in the maturation of IL-1 $\beta$ upon TLR3 activation has been demonstrated. Surprisingly, poly (I:C)-stimulated-IL- $1 \beta$ production was still observed in caspase-1-deficient cells but was suppressed by caspase- 8 inhibitors and caspase- 8 RNAi silencing. Accordingly, researchers proposed that a comparable TRIFRIP1-FADD-caspase-8 cascade leads to IL- $1 \beta$ production. ${ }^{126}$ Moreover, melanoma cells and $\mathrm{HaCaT}$ human keratinocytes stimulated by poly (I:C) were shown to be susceptible to apoptosis associated with the TLR3/TRIF/caspase- 8 complex ${ }^{127}$ (Figure 4).

By contrast, caspase- 8 has also been shown to prevent inflammasome activity, IFN response and necroptosis, a programmed cell death resulting from caspase-8, RIPK1 and RIPK3. ${ }^{128,129}$ Compared to WT or Ripk ${ }^{-/-}$BMDMs, Ripk3 ${ }^{-/-}$ Casp $8^{-/-}$BMDMs have been shown to display decreased levels of IL-1 $\beta$ and poly (I:C) /TLR3-induced inflammasome priming. ${ }^{130}$

TLR7 and TLR9 recognize ssRNA and unmethylated CpG DNA, respectively, in endosomes and are tightly connected to the pathogenesis of SLE (systemic lupus erythematosus). Except for TLR3, most TLRs signal through MyD88 to activate NF- $\kappa B$ signaling. Caspase- 8 also reportedly serves as a molecular rheostat to restrict MyD88-dependent dendritic cell activation. ${ }^{131}$ When stimulated by CpG (TLR9 agonist) or imiquimod (TLR7 agonist), Cre ${ }^{\mathrm{CD} 11 \mathrm{c}} \mathrm{Casp} 8^{\mathrm{f} / / \mathrm{fl}}$ BMDCs exhibit increased expression of IL-12/23p40, TNF $\alpha$, IL- 6 and IL-1 $\beta$ without inducing cell death. The loss of caspase- 8 in DCs causes hyper-responsiveness to TLR activation, indicating that caspase-8 suppresses MyD88 signaling. However, it was proposed that this suppressive activity of caspase- 8 is related to MyD88 recruitment but not its catalytic activity. ${ }^{131}$ These data provide a relationship between caspase- 8 and augmented TLR responses to pathogenetic stimuli.

Caspase-8-deficient keratinocytes exhibit enhanced gene activation by DNA transfection. Meanwhile, TBK1 and IRF3 are constitutively phosphorylated in the epidermis of the Casp $8^{\mathrm{F} /-} \mathrm{K} 5$-Cre mice, and the well-known ISGs are also induced. Moreover, in response to DNA transfection, caspase-8-deficient keratinocytes yield a higher level of IRF3targeted genes than the caspase-8-overexpressed cells. In addition, since MyD88, TRIF and most TLR adapters were ruled out, caspase- 8 was further proven to regulate IRF3 or TBK1 directly, but the exact molecular mechanism needs to be further clarified ${ }^{132}$ (Figure 4).

\section{Caspases regulate viral ER stress-induced apoptosis}

Caspase-12 is an inflammatory caspase located in the endoplasmic reticulum (ER). Early studies indicated that caspase- 12 is an ER stress response caspase. ${ }^{133}$ Unbalanced ER-Ca ${ }^{2+}$ homeostasis and accumulated misfolded, unassembled or aggregated proteins in the ER lumen reportedly stimulate ER stress signaling. Furthermore, viruses utilize the ER as an integrated unit for their life cycles, leading to some levels of ER stress. Mild ER stress affects protein synthesis initiation and can downregulate cell proliferation, whereas acute or persistent ER stress can cause cell death induced by caspase-12. ${ }^{134}$ Studies incaspase-12-deficient mice emphasized the principle function of caspase-12 in ER stress-mediated apoptosis. ${ }^{133}$ In addition, viral infection might induce caspase-12-dependent apoptosis. ${ }^{18,135}$ The RNA virus BVDV (bovine viral diarrhea virus) and related flavivirus-infected MDBK (Madin-Darby bovine kidney) cells have increased expression of caspase- 12 and decreased levels of the anti-apoptotic protein Bcl-2. Caspase- 12 cleaves pro-caspase- 7 to its active caspase- 7 form. The detailed mechanisms of how ER stress signaling activates caspase-12 have not yet been elucidated. However, current studies have proven that other cytosolic caspases can be recruited by activated caspase- 12 in the ER membrane, and thus, the apoptotic signal is greatly boosted. ${ }^{136}$ In A549 epithelial cells infected with RSV, casapse-9 is not activated, caspases- 3 and -8 are modestly activated, and caspase- 12 is strongly activated. Moreover, RSV-stimulated apoptosis seems to occur through a caspase-12-dependent ER stress response, which is uncoupled from NF- $\mathrm{KB}$ activation. ${ }^{135}$

\section{CONCLUSIONS}

Viral PAMPs are recognized differentially by innate PRRs to initiate antiviral immune responses in a systematic manner. The complicated antiviral innate immune signaling network has co-evolved with viruses to defend against and restrain 
autoimmunity via a sophisticated state-of-the-art feedback scheme. The caspase family members are architects of the body and sit at the nexus of this dynamic regulatory framework. In the past few decades, significant advances in understanding the critical functions of caspases for organism homeostasis and especially novel and exciting discoveries have unveiled the multifaceted nature of individual caspases in the antiviral innate immune system. Studies on caspases have provided an interesting point of view that caspases act as molecular 'decision-makers' because of their ability to fine-tune antiviral innate immunity and because caspases have both proinflammatory and anti-inflammatory functions. Moreover, recent studies have uncovered the capacity of caspases to mediate nearly all the PRRs involved in innate immunity by acting as a molecular switch on whether to respond to an insult by initiating inflammation or potentiating I-IFN response to eliminate invading viruses, or by preventing inflammation to maintain immunological silence by dismantling insulted or damaged cells. Increasingly distinguished and sophisticated discoveries have challenged the traditional definition of caspase family members. However, contradiction and controversy regarding the regulation of innate immunity by caspases exist, and the understanding of the molecular basis of these phenomena remains in infancy. Caspases are double-edged swords. The inappropriate activation of caspases and dysregulation of the antiviral innate immune signaling controlled by caspases has dire consequences for human health and is associated with an extensive list of human diseases. Ongoing studies will provide us with a more comprehensive understanding of caspase mechanisms and may shed new light on therapeutic options for the various caspase-related human diseases.

\section{CONFLICT OF INTEREST}

The authors declare no conflict of interest.

\section{ACKNOWLEDGEMENTS}

We thank members of the Jiang Laboratory for helpful discussions. We apologize for being unable to include the important contributions from all researchers in the field due to space limitations. Recent and ongoing studies performed in the Jiang Laboratory are supported by grants from the Chinese Ministry of Science and Technology (2014CB542600 and 2015CC040097) and the China Natural Science Foundation (31230023, 91129000 and 81621001).

1 Takeuchi O, Akira S. Pattern recognition receptors and inflammation. Cell 2010; 140: 805-820.

2 Allen IC, Scull MA, Moore CB, Holl EK, McElvania-TeKippe E, Taxman DJ et al. The NLRP3 inflammasome mediates in vivo innate immunity to influenza A virus through recognition of viral RNA. Immunity 2009; 30: 556-565.

3 Yoneyama M, Kikuchi M, Matsumoto K, Imaizumi T, Miyagishi M, Taira $\mathrm{K}$ et al. Shared and unique functions of the DExD/H-box helicases RIG-I, MDA5, and LGP2 in antiviral innate immunity. J Immunol 2005; 175: 2851-2858.

4 Yoneyama M, Kikuchi M, Natsukawa T, Shinobu N, Imaizumi T, Miyagishi $\mathrm{M}$ et al. The RNA helicase RIG-I has an essential function in double-stranded RNA-induced innate antiviral responses. Nat Immunol 2004; 5: 730-737.

5 Yoh SM, Schneider M, Seifried J, Soonthornvacharin S, Akleh RE, Olivieri KC et al. PQBP1 is a proximal sensor of the cGAS-dependent innate response to HIV-1. Cell 2015; 161: 1293-1305.

6 Ferguson BJ, Mansur DS, Peters NE, Ren H, Smith GL. DNA-PK is a DNA sensor for IRF-3-dependent innate immunity. eLife 2012; 1: e00047.

7 Xia P, Wang S, Ye B, Du Y, Huang G, Zhu P et al. Sox2 functions as a sequence-specific DNA sensor in neutrophils to initiate innate immunity against microbial infection. Nat Immunol 2015; 16 : 366-375.

8 Kondo T, Kobayashi J, Saitoh T, Maruyama K, Ishii KJ, Barber GN et al. DNA damage sensor MRE11 recognizes cytosolic doublestranded DNA and induces type I interferon by regulating STING trafficking. Proc Natl Acad USA 2013; 110: 2969-2974.

9 Ablasser A, Goldeck M, Cavlar T, Deimling T, Witte G, Rohl I et al. cGAS produces a 2'-5'-linked cyclic dinucleotide second messenger that activates STING. Nature 2013; 498: 380-384.

10 Burckstummer T, Baumann C, Bluml S, Dixit E, Durnberger G, Jahn $\mathrm{H}$ et al. An orthogonal proteomic-genomic screen identifies AIM2 as a cytoplasmic DNA sensor for the inflammasome. Nat Immunol 2009; 10: 266-272.

11 Fernandes-Alnemri T, Yu JW, Datta P, Wu J, Alnemri ES. AIM2 activates the inflammasome and cell death in response to cytoplasmic DNA. Nature 2009; 458: 509-513.

12 Hornung V, Ablasser A, Charrel-Dennis M, Bauernfeind F, Horvath G, Caffrey DR et al. AIM2 recognizes cytosolic dsDNA and forms a caspase-1-activating inflammasome with ASC. Nature 2009; 458: 514-518.

13 Kawai T, Akira S. The role of pattern-recognition receptors in innate immunity: update on Toll-like receptors. Nat Immunol 2010; 11: 373-384.

14 Nie Y, Wang YY. Innate immune responses to DNA viruses. Protein Cell 2013; 4: 1-7.

15 Pichlmair A, Reis e Sousa C. Innate recognition of viruses. Immunity 2007; 27: 370-383.

16 Ramos HJ, Gale M Jr.. RIG-I like receptors and their signaling crosstalk in the regulation of antiviral immunity. Curr Opin Virol 2011; 1: 167-176.

17 Roberts TL, Idris A, Dunn JA, Kelly GM, Burnton CM, Hodgson S et al. HIN-200 proteins regulate caspase activation in response to foreign cytoplasmic DNA. Science 2009; 323: 1057-1060.

18 Jordan R, Wang L, Graczyk TM, Block TM, Romano PR. Replication of a cytopathic strain of bovine viral diarrhea virus activates PERK and induces endoplasmic reticulum stress-mediated apoptosis of MDBK cells. J Virol 2002; 76: 9588-9599.

19 Mcllwain DR, Berger T, Mak TW. Caspase functions in cell death and disease. Cold Spring Harb Perspect Biol 2013; 5: a008656.

20 Shalini S, Dorstyn L, Dawar S, Kumar S. Old, new and emerging functions of caspases. Cell Death Differ 2015; 22: 526-539.

21 Kumar S. Caspase function in programmed cell death. Cell Death Differ 2007; 14: 32-43.

22 Latz E, Xiao TS, Stutz A. Activation and regulation of the inflammasomes. Nat Rev Immunol 2013; 13: 397-411.

23 Lamkanfi M, Dixit VM. Mechanisms and functions of inflammasomes. Cell 2014; 157: 1013-1022.

24 Man SM, Kanneganti TD. Regulation of inflammasome activation. Immunol Rev 2015; 265: 6-21.

25 Degterev A, Boyce M, Yuan J. A decade of caspases. Oncogene 2003; 22: 8543-8567.

26 Fuentes-Prior P, Salvesen GS. The protein structures that shape caspase activity, specificity, activation and inhibition. Biochem J 2004; 384 (Pt 2): 201-232.

27 Li P, Nijhawan D, Budihardjo I, Srinivasula SM, Ahmad M, Alnemri ES et al. Cytochrome $c$ and dATP-dependent formation of Apaf-1/ caspase-9 complex initiates an apoptotic protease cascade. Cell 1997; 91: 479-489.

28 Acehan D, Jiang X, Morgan DG, Heuser JE, Wang X, Akey CW. Three-dimensional structure of the apoptosome: implications for assembly, procaspase-9 binding, and activation. Mol Cell 2002; 9: 423-432.

29 Ashkenazi A, Dixit VM. Death receptors: signaling and modulation. Science 1998; 281: 1305-1308. 
30 Li H, Zhu H, Xu CJ, Yuan J. Cleavage of BID by caspase 8 mediates the mitochondrial damage in the Fas pathway of apoptosis. Cell 1998; 94: 491-501.

31 Feoktistova M, Geserick P, Kellert B, Dimitrova DP, Langlais C, Hupe $\mathrm{M}$ et al. clAPs block ripoptosome formation, a RIP1/caspase-8 containing intracellular cell death complex differentially regulated by cFLIP isoforms. Mol Cell 2011; 43: 449-463.

32 Blander JM. A long-awaited merger of the pathways mediating host defence and programmed cell death. Nat Rev Immunol 2014; 14: 601-618.

33 Brenner D, Blaser H, Mak TW. Regulation of tumour necrosis factor signalling: live or let die. Nat Rev Immunol 2015; 15: 362-374.

34 Kanneganti TD. Central roles of NLRs and inflammasomes in viral infection. Nat Rev Immunol 2010; 10: 688-698.

35 Kanneganti TD, Body-Malapel M, Amer A, Park JH, Whitfield J, Franchi $\mathrm{L}$ et al. Critical role for cryopyrin/Nalp3 in activation of caspase-1 in response to viral infection and double-stranded RNA. J Biol Chem 2006; 281: 36560-36568.

36 Kanneganti TD, Ozoren N, Body-Malapel M, Amer A, Park JH, Franchi $L$ et al. Bacterial RNA and small antiviral compounds activate caspase-1 through cryopyrin/Nalp3. Nature 2006; 440: 233-236.

37 Ichinohe T, Lee HK, Ogura Y, Flavell R, Iwasaki A. Inflammasome recognition of influenza virus is essential for adaptive immune responses. J Exp Med 2009; 206: 79-87.

38 Thomas PG, Dash P, Aldridge JR Jr., Ellebedy AH, Reynolds C, Funk AJ et al. The intracellular sensor NLRP3 mediates key innate and healing responses to influenza A virus via the regulation of caspase- 1 . Immunity 2009; 30: 566-575.

39 Poeck H, Bscheider M, Gross O, Finger K, Roth S, Rebsamen M et al. Recognition of RNA virus by RIG-I results in activation of CARD9 and inflammasome signaling for interleukin 1 beta production. Nat Immunol 2010; 11: 63-69.

40 Hagar JA, Powell DA, Aachoui Y, Ernst RK, Miao EA. Cytoplasmic LPS activates caspase-11: implications in TLR4-independent endotoxic shock. Science 2013; 341: 1250-1253.

41 Kayagaki N, Wong MT, Stowe IB, Ramani SR, Gonzalez LC, A kashi-Takamura $\mathrm{S}$ et al. Noncanonical inflammasome activation by intracellular LPS independent of TLR4. Science 2013; 341: 1246-1249.

42 Vigano E, Diamond CE, Spreafico R, Balachander A, Sobota RM, Mortellaro A. Human caspase- 4 and caspase- 5 regulate the one-step non-canonical inflammasome activation in monocytes. Nat Commun 2015; 6: 8761

43 Broz P, Dixit VM. Inflammasomes: mechanism of assembly, regulation and signalling. Nat Rev Immunol 2016; 16: 407-420.

44 Luthi AU, Cullen SP, McNeela EA, Duriez PJ, Afonina IS, Sheridan C et al. Suppression of interleukin-33 bioactivity through proteolysis by apoptotic caspases. Immunity 2009; 31: 84-98.

45 Fink SL, Bergsbaken T, Cookson BT. Anthrax lethal toxin and Salmonella elicit the common cell death pathway of caspase-1dependent pyroptosis via distinct mechanisms. Proc Natl Acad Sci USA 2008; 105: 4312-4317.

46 Schmitz J, Owyang A, Oldham E, Song Y, Murphy E, McClanahan TK et al. IL-33, an interleukin-1-like cytokine that signals via the IL-1 receptor-related protein ST2 and induces T helper type 2-associated cytokines. Immunity 2005; 23: 479-490.

47 Rintahaka J, Wiik D, Kovanen PE, Alenius H, Matikainen S. Cytosolic antiviral RNA recognition pathway activates caspases 1 and 3. J Immunol 2008; 180: 1749-1757.

48 Melchjorsen J, Jensen SB, Malmgaard L, Rasmussen SB, Weber F, Bowie AG et al. Activation of innate defense against a paramyxovirus is mediated by RIG-I and TLR7 and TLR8 in a cell-typespecific manner. J Virol 2005; 79: 12944-12951.

49 Rothenfusser S, Goutagny N, DiPerna G, Gong M, Monks BG, Schoenemeyer A et al. The RNA helicase Lgp2 inhibits TLRindependent sensing of viral replication by retinoic acidinducible gene-I. J Immunol 2005; 175: 5260-5268.

50 Fredericksen BL, Gale M Jr.. West Nile virus evades activation of interferon regulatory factor 3 through RIG-I-dependent and -independent pathways without antagonizing host defense signaling. J Virol 2006; 80: 2913-2923.

51 Hornung V, Ellegast J, Kim S, Brzozka K, Jung A, Kato $\mathrm{H}$ et al. 5'-Triphosphate RNA is the ligand for RIG-I. Science 2006; 314 : 994-997.
52 Kato H, Takeuchi O, Sato S, Yoneyama M, Yamamoto M, Matsui K et al. Differential roles of MDA5 and RIG-I helicases in the recognition of RNA viruses. Nature 2006; 441: 101-105.

53 Pichlmair A, Schulz O, Tan CP, Naslund TI, Liljestrom P, Weber F et al. RIG-I-mediated antiviral responses to single-stranded RNA bearing 5'-phosphates. Science 2006; 314: 997-1001.

54 Liu P, Jamaluddin M, Li K, Garofalo RP, Casola A, Brasier AR. Retinoic acid-inducible gene I mediates early antiviral response and Toll-like receptor 3 expression in respiratory syncytial virus-infected airway epithelial cells. J Virol 2007; 81: 1401-1411.

55 Mikkelsen SS, Jensen SB, Chiliveru S, Melchjorsen J, Julkunen I, Gaestel M et al. RIG-I-mediated activation of p38 MAPK is essential for viral induction of interferon and activation of dendritic cells: dependence on TRAF2 and TAK1. J Biol Chem 2009; 284: 10774-10782.

56 Rathinam VA, Jiang Z, Waggoner SN, Sharma S, Cole LE, Waggoner L et al. The AIM2 inflammasome is essential for host defense against cytosolic bacteria and DNA viruses. Nat Immunol 2010; 11: 395-402.

57 Ekchariyawat $\mathrm{P}$, Hamel R, Bernard E, Wichit S, Surasombatpattana P, Talignani $L$ et al. Inflammasome signaling pathways exert antiviral effect against Chikungunya virus in human dermal fibroblasts. Infect Genet Evol 2015; 32: 401-408.

58 Hamel R, Dejarnac O, Wichit S, Ekchariyawat $P$, Neyret A, Luplertlop $\mathrm{N}$ et al. Biology of Zika virus infection in human skin cells. J Virol 2015; 89: 8880-8896.

59 Kerur N, Veettil MV, Sharma-Walia N, Bottero V, Sadagopan S, Otageri $\mathrm{P}$ et al. IFI16 acts as a nuclear pathogen sensor to induce the inflammasome in response to Kaposi Sarcoma-associated herpesvirus infection. Cell Host Microbe 2011; 9: 363-375.

60 Jakobsen MR, Bak RO, Andersen A, Berg RK, Jensen SB, Tengchuan $\mathrm{J}$ et al. IFI16 senses DNA forms of the lentiviral replication cycle and controls HIV-1 replication. Proc Natl Acad Sci USA 2013; 110: E4571-E4580.

61 Doitsh G, Galloway NLK, Geng X, Yang ZY, Monroe KM, Zepeda O et al. Cell death by pyroptosis drives CD4 T-cell depletion in HIV-1 infection. Nature 2014; 505: 509-514.

62 Monroe KM, Yang Z, Johnson JR, Geng X, Doitsh G, Krogan NJ et al. IFI16 DNA sensor is required for death of lymphoid CD4 T cells abortively infected with HIV. Science 2014; 343: 428-432.

63 Guillot L, Le Goffic R, Bloch S, Escriou N, Akira S, Chignard M et al. Involvement of toll-like receptor 3 in the immune response of lung epithelial cells to double-stranded RNA and influenza A virus. J Biol Chem 2005; 280: 5571-5580.

64 Koyama S, Ishii KJ, Kumar H, Tanimoto T, Coban C, Uematsu S et al. Differential role of TLR- and RLR-signaling in the immune responses to influenza A virus infection and vaccination. J Immunol 2007; 179: 4711-4720.

65 Ichinohe T, Pang IK, Iwasaki A. Influenza virus activates inflammasomes via its intracellular M2 ion channel. Nat Immunol 2010; 11: 404-410.

66 Delaloye J, Roger T, Steiner-Tardivel QG, Le Roy D, Knaup Reymond $M$, Akira $S$ et al. Innate immune sensing of modified vaccinia virus Ankara (MVA) is mediated by TLR2-TLR6, MDA-5 and the NALP3 inflammasome. PLoS Pathog 2009; 5: e1000480.

67 Jones JW, Kayagaki N, Broz P, Henry T, Newton K, O'Rourke K et al. Absent in melanoma 2 is required for innate immune recognition of Francisella tularensis. Proc Natl Acad Sci USA 2010; 107: 9771-9776.

68 Cookson BT, Brennan MA. Pro-inflammatory programmed cell death. Trends Microbiol 2001; 9: 113-114.

69 Jorgensen I, Miao EA. Pyroptotic cell death defends against intracelIular pathogens. Immunol Rev 2015; 265: 130-142.

70 Zychlinsky A, Prevost MC, Sansonetti PJ. Shigella flexneri induces apoptosis in infected macrophages. Nature 1992; 358: 167-169.

71 Miao EA, Leaf IA, Treuting PM, Mao DP, Dors M, Sarkar A et al. Caspase-1-induced pyroptosis is an innate immune effector mechanism against intracellular bacteria. Nat Immunol 2010; 11: 1136-1142.

72 Kayagaki N, Stowe IB, Lee BL, O'Rourke K, Anderson K, Warming S et al. Caspase-11 cleaves gasdermin D for non-canonical inflammasome signalling. Nature 2015; 526: 666-671. 
73 Shi J, Zhao Y, Wang K, Shi X, Wang Y, Huang $\mathrm{H}$ et al. Cleavage of GSDMD by inflammatory caspases determines pyroptotic cell death. Nature 2015; 526: 660-665.

74 Agard NJ, Maltby D, Wells JA. Inflammatory stimuli regulate caspase substrate profiles. Mol Cell Proteomics 2010; 9: 880-893.

75 Malireddi RKS, Ippagunta S, Lamkanfi M, Kanneganti TD. Cutting edge: proteolytic inactivation of poly(ADP-ribose) polymerase 1 by the Nlrp3 and Nirc4 inflammasomes. J Immunol 2010; 185: 3127-3130.

76 Knodler LA, Crowley SM, Sham HP, Yang HJ, Wrande M, Ma CX et al. Noncanonical inflammasome activation of caspase-4/caspase-11 mediates epithelial defenses against enteric bacterial pathogens. Cell Host Microbe 2014; 16: 249-256.

77 Aachoui Y, Leaf IA, Hagar JA, Fontana MF, Campos CG, Zak DE et al. Caspase-11 protects against bacteria that escape the vacuole. Science 2013; 339: 975-978.

78 Miao EA, Leaf IA, Treuting PM, Mao DP, Dors M, Sarkar A et al. Caspase-1-induced pyroptosis is an innate immune effector mechanism against intracellular bacteria. Nat Immunol 2010; 11: 1136-U94.

79 Sellin ME, Muller AA, Felmy B, Dolowschiak T, Diard M, Tardivel A et al. Epithelium-intrinsic NAIP/NLRC4 inflammasome drives infected enterocyte expulsion to restrict salmonella replication in the intestinal mucosa. Cell Host Microbe 2014; 16: 237-248.

80 Man SM, Kanneganti TD. Converging roles of caspases in inflammasome activation, cell death and innate immunity. Nat Rev Immunol 2016; 16: 7-21.

81 Shi JJ, Zhao Y, Wang YP, Gao WQ, Ding JJ, Li P et al. Inflammatory caspases are innate immune receptors for intracellular LPS. Nature 2014; 514: 187-192.

82 Kayagaki N, Warming S, Lamkanfi M, Vande Walle L, Louie S, Dong J et al. Non-canonical inflammasome activation targets caspase-11. Nature 2011; 479: 117-U46.

83 Rongvaux A, Jackson R, Harman CCD, Li T, West AP, de Zoete MR et al. Apoptotic caspases prevent the induction of type I interferons by mitochondrial DNA. Cell 2014; 159: 1563-1577.

84 White MJ, McArthur K, Metcalf D, Lane RM, Cambier JC, Herold MJ et al. Apoptotic caspases suppress mtDNA-induced STING-mediated type I IFN production. Cell 2014; 159: 1549-1562.

85 Cai $X$, Chiu YH, Chen ZJ. The cGAS-cGAMP-STING pathway of cytosolic DNA sensing and signaling. Mol Cell 2014; 54: 289-296.

86 Schoggins JW, MacDuff DA, Imanaka N, Gainey MD, Shrestha B, Eitson JL et al. Pan-viral specificity of IFN-induced genes reveals new roles for cGAS in innate immunity. Nature 2014; 505: 691-695.

$87 \mathrm{Li} \mathrm{XD,} \mathrm{Wu} \mathrm{J,} \mathrm{Gao} \mathrm{D,} \mathrm{Wang} \mathrm{H,} \mathrm{Sun} \mathrm{L,} \mathrm{Chen} \mathrm{ZJ.} \mathrm{Pivotal} \mathrm{roles} \mathrm{of}$ cGAS-cGAMP signaling in antiviral defense and immune adjuvant effects. Science 2013; 341: 1390-1394.

88 Ishikawa H, Ma Z, Barber GN. STING regulates intracellular DNA-mediated, type I interferon-dependent innate immunity. Nature 2009; 461: 788-792.

89 Lam E, Stein S, Falck-Pedersen E. Adenovirus detection by the cGAS/ STING/TBK1 DNA sensing cascade. J Virol 2014; 88: 974-981.

90 Sunthamala N, Thierry F, Teissier S, Pientong C, Kongyingyoes B, Tangsiriwatthana $\mathrm{T}$ et al. E2 proteins of high risk human papillomaviruses down-modulate STING and IFN-kappa transcription in keratinocytes. PloS One 2014; 9: e91473.

91 Paijo J, Doring M, Spanier J, Grabski E, Nooruzzaman M, Schmidt T et al. cGAS senses human cytomegalovirus and induces type I interferon responses in human monocyte-derived cells. PLoS Pathog 2016; 12: e1005546.

$92 \mathrm{Hu} \mathrm{MM}$, Shu HB. Multifaceted roles of TRIM38 in innate immune and inflammatory responses. Cell Mol Immunol 2017; 14: 331-338.

$93 \mathrm{Wu} \mathrm{J}$, Chen ZJ. Innate immune sensing and signaling of cytosolic nucleic acids. Annu Rev Immunol 2014; 32: 461-488.

94 Chen $H$, Sun H, You F, Sun W, Zhou X, Chen L et al. Activation of STAT6 by STING is critical for antiviral innate immunity. Cell 2011; 147: 436-446.

95 Christensen MH, Paludan SR. Viral evasion of DNA-stimulated innate immune responses. Cell Mol Immunol 2017; 14: 4-13.

96 West AP, Khoury-Hanold W, Staron M, Tal MC, Pineda CM, Lang SM et al. Mitochondrial DNA stress primes the antiviral innate immune response. Nature 2015; 520: 553-557.
97 Crawford ED, Seaman JE, Agard N, Hsu GW, Julien O, Mahrus S et al. The DegraBase: a database of proteolysis in healthy and apoptotic human cells. Mol Cell Proteomics 2013; 12: 813-824.

98 Wang $Y$, Ning X, Gao P, Wu S, Sha M, Lv M et al. Inflammasome activation triggers caspase-1-mediated cleavage of cGAS to regulate responses to DNA virus infection. Immunity 2017; 46: 393-404.

99 Tao J, Zhang XW, Jin J, Du XX, Lian T, Yang J et al. Non-specific DNA binding of cGAS N-terminus promotes cGAS activation. J Immunol 2017; 198: 3627-3636.

100 Takahashi K, Kawai T, Kumar H, Sato S, Yonehara S, Akira S. Roles of caspase-8 and caspase-10 in innate immune responses to double-stranded RNA. J Immunol 2006; 176: 4520-4524.

101 Rajput A, Kovalenko A, Bogdanov K, Yang SH, Kang TB, Kim JC et al. RIG-I RNA helicase activation of IRF3 transcription factor is negatively regulated by caspase-8-mediated cleavage of the RIP1 protein. Immunity 2011; 34: 340-351.

102 Lin Y, Devin A, Rodriguez Y, Liu ZG. Cleavage of the death domain kinase RIP by caspase-8 prompts TNF-induced apoptosis. Genes Dev 1999; 13: 2514-2526.

103 Feng S, Yang Y, Mei Y, Ma L, Zhu DE, Hoti N et al. Cleavage of RIP3 inactivates its caspase-independent apoptosis pathway by removal of kinase domain. Cell Signal 2007; 19: 2056-2067.

104 O'Donnell MA, Perez-Jimenez E, Oberst A, Ng A, Massoumi R, Xavier $\mathrm{R}$ et al. Caspase 8 inhibits programmed necrosis by processing CYLD. Nat Cell Biol 2011; 13: 1437-1442.

105 Sears N, Sen GC, Stark GR, Chattopadhyay S. Caspase-8-mediated cleavage inhibits IRF-3 protein by facilitating its proteasomemediated degradation. J Biol Chem 2011; 286: 33037-33044.

106 Staal J, Bekaert T, Beyaert R. Regulation of NF-kappaB signaling by caspases and MALT1 paracaspase. Cell Res 2011; 21: 40-54.

107 Holm GH, Zurney J, Tumilasci V, Leveille S, Danthi P, Hiscott J et al. Retinoic acid-inducible gene-I and interferon-beta promoter stimulator-1 augment proapoptotic responses following mammalian reovirus infection via interferon regulatory factor-3. J Biol Chem 2007; 282: 21953-21961.

108 Lei Y, Moore CB, Liesman RM, O'Connor BP, Bergstralh DT, Chen ZJ et al. MAVS-mediated apoptosis and its inhibition by viral proteins. PLoS One 2009; 4: e5466.

109 Chattopadhyay S, Marques JT, Yamashita M, Peters KL, Smith K, Desai $A$ et al. Viral apoptosis is induced by IRF-3-mediated activation of Bax. EMBO J 2010; 29: 1762-1773.

110 Yu CY, Chiang RL, Chang TH, Liao CL, Lin YL. The interferon stimulator mitochondrial antiviral signaling protein facilitates cell death by disrupting the mitochondrial membrane potential and by activating caspases. J Virol 2010; 84: 2421-2431.

111 Besch R, Poeck H, Hohenauer T, Senft D, Hacker G, Berking C et al. Proapoptotic signaling induced by RIG-I and MDA-5 results in type I interferon-independent apoptosis in human melanoma cells. J Clin Invest 2009; 119: 2399-2411.

112 Li HM, Fujikura D, Harada T, Uehara J, Kawai T, Akira S et al. IPS-1 is crucial for DAP3-mediated anoikis induction by caspase-8 activation. Cell Death Differ 2009; 16: 1615-1621.

113 Buskiewicz IA, Koenig A, Huber SA, Budd RC. Caspase-8 and FLIP regulate RIG-I/MDA5-induced innate immune host responses to picornaviruses. Future Virol 2012; 7: 1221-1236.

114 El Maadidi S, Faletti L, Berg B, Wenzl C, Wieland K, Chen ZJ et al. A novel mitochondrial MAVS/Caspase-8 platform links RNA virusinduced innate antiviral signaling to Bax/Bak-independent apoptosis. J Immunol 2014; 192: 1171-1183.

115 Drahos J, Racaniello VR. Cleavage of IPS-1 in cells infected with human rhinovirus. J Virol 2009; 83: 11581-11587.

116 Madan V, Castello A, Carrasco L. Viroporins from RNA viruses induce caspase-dependent apoptosis. Cell Microbiol 2008; 10: 437-451.

117 Wang $\mathrm{P}$, Arjona A, Zhang Y, Sultana H, Dai J, Yang L et al. Caspase12 controls West Nile virus infection via the viral RNA receptor RIG-I. Nat Immunol 2010; 11: 912-919.

118 Morizot A, Saleh M. Non-apoptotic functions of cell death effectors in inflammation and innate immunity. Microbes Infect 2012; 14: 1241-1253.

119 Diehl GE, Yue HH, Hsieh K, Kuang AA, Ho M, Morici LA et al. TRAIL-R as a negative regulator of innate immune cell responses. Immunity 2004; 21: 877-889. 
120 Lamkanfi M, Kalai M, Saelens X, Declercq W, Vandenabeele P. Caspase-1 activates nuclear factor of the kappa-enhancer in B cells independently of its enzymatic activity. J Biol Chem 2004; 279: 24785-24793.

121 Launay S, Hermine O, Fontenay M, Kroemer G, Solary E, Garrido C. Vital functions for lethal caspases. Oncogene 2005; 24: 5137-5148.

122 Chun HJ, Zheng L, Ahmad M, Wang J, Speirs CK, Siegel RM et al. Pleiotropic defects in lymphocyte activation caused by caspase- 8 mutations lead to human immunodeficiency. Nature 2002; 419: 395-399.

123 Su H, Bidere N, Zheng L, Cubre A, Sakai K, Dale J et al. Requirement for caspase-8 in NF-kappaB activation by antigen receptor. Science 2005; 307: 1465-1468.

124 Lemmers B, Salmena L, Bidere N, Su H, Matysiak-Zablocki E, Murakami $\mathrm{K}$ et al. Essential role for caspase- 8 in Toll-like receptors and NFkappaB signaling. J Biol Chem 2007; 282: 7416-7423.

$125 \mathrm{Hu}$ WH, Johnson H, Shu HB. Activation of NF-kappaB by FADD, casper, and caspase-8. J Biol Chem 2000; 275: 10838-10844.

126 Maelfait J, Vercammen E, Janssens S, Schotte P, Haegman M, Magez $S$ et al. Stimulation of Toll-like receptor 3 and 4 induces interleukin-1beta maturation by caspase-8. J Exp Med 2008; 205: 1967-1973.

127 Weber A, Kirejczyk Z, Besch R, Potthoff S, Leverkus M, Hacker G. Proapoptotic signalling through Toll-like receptor-3 involves TRIF-dependent activation of caspase- 8 and is under the control of inhibitor of apoptosis proteins in melanoma cells. Cell Death Differ 2010; 17: 942-951.

128 Holler N, Zaru R, Micheau O, Thome M, Attinger A, Valitutti S et al. Fas triggers an alternative, caspase-8-independent cell death pathway using the kinase RIP as effector molecule. Nat Immunol 2000; 1: 489-495.
129 Kang TB, Yang SH, Toth B, Kovalenko A, Wallach D. Caspase-8 blocks kinase RIPK3-mediated activation of the NLRP3 inflammasome. Immunity 2013; 38: 27-40.

130 Allam R, Lawlor KE, Yu EC, Mildenhall AL, Moujalled DM, Lewis RS et al. Mitochondrial apoptosis is dispensable for NLRP3 inflammasome activation but non-apoptotic caspase- 8 is required for inflammasome priming. EMBO Rep 2014; 15: 982-990.

131 Cuda CM, Misharin AV, Gierut AK, Saber R, Haines GK, Hutcheson J et al. Caspase-8 acts as a molecular rheostat to limit RIPK1-and MyD88-mediated dendritic cell activation. J Immunol 2014; 192: 5548-5560.

132 Kovalenko A, Kim JC, Kang TB, Rajput A, Bogdanov K, Dittrich-Breiholz 0 et al. Caspase-8 deficiency in epidermal keratinocytes triggers an inflammatory skin disease. J Exp Med 2009; 206: 2161-2177.

133 Nakagawa T, Zhu H, Morishima N, Li E, Xu J, Yankner BA et al. Caspase-12 mediates endoplasmic-reticulum-specific apoptosis and cytotoxicity by amyloid-beta. Nature 2000; 403: 98-103.

134 Kaufman RJ. Stress signaling from the lumen of the endoplasmic reticulum: coordination of gene transcriptional and translational controls. Genes Dev 1999; 13: 1211-1233.

135 Bitko V, Barik S. An endoplasmic reticulum-specific stress-activated caspase (caspase-12) is implicated in the apoptosis of A549 epithelial cells by respiratory syncytial virus. J Cell Biochem 2001; 80: 441-454.

136 Rao RV, Hermel E, Castro-Obregon S, del Rio G, Ellerby LM, Ellerby $\mathrm{HM}$ et al. Coupling endoplasmic reticulum stress to the cell death program-mechanism of caspase activation. J Biol Chem 2001; 276: 33869-33874.

137 Tenev T, Bianchi K, Darding M, Broemer M, Langlais C, Wallberg F et al. The ripoptosome, a signaling platform that assembles in response to genotoxic stress and loss of IAPs. Mol Cell 2011; 43: 432-448. 